\title{
O DETERMINISMO RACIAL E GEOGRÁFICO NO DISCURSO GEOPOLÍTICO MODERNO/COLONIAL: POR UMA GEOPOLÍTICA DECOLONIAL ${ }^{1}$
}

\author{
ENVIRONMENTAL DETERMINISM IN THE MODERN/COLONIAL GEOPOLITICAL \\ DISCOURSE: FOR A DECOLONIAL GEOPOLITICS
}

Pedro Diniz Rocha

Mestrando em Relações Internacionais pela Pontifícia Universidade Católica de Minas Gerais, pedro.diniz.rocha@gmail.com

\section{Resumo}

A expansão do sistema moderno/colonial a partir das grandes viagens nos séculos quinze e dezesseis originou a construção de uma diferenciação primeira entre conquistadores e colonizados baseada na ideia de raça. Esta se tornou então elemento fundante e constitutivo de relações de dominação, articulando e cristalizando o poder no espaço geográfico. $\mathrm{O}$ objetivo deste artigo, então, é o de analisar teses geopolíticas fundadas inicialmente sobre 0 prisma do determinismo racial e geográfico em fins do século dezenove e início do século vinte, de forma a compreender se seu discurso de autoridade legitima à época nova expansão colonial e a intensificação da violência e do domínio europeu sobre o globo, tendo em vista que remete a classificação social de agrupamentos humanos a partir da ideia de raça e de seu ambiente geográfico. Em vista disto, será realizada uma breve genealogia do discurso determinista no pensamento ocidental e a análise de sua influência nas teses geopolíticas de Friedrich Ratzel, Ellen Semple e Ellsworth Huntington e alguns de seus paralelos e contrapontos com a geopolítica francesa, em especial a de Paul Vidal de la Blache. Espera-se, a partir deste artigo, ampliar o chamado para construção de uma geopolítica subalterna que aponte para as vicissitudes do discurso geopolítico moderno/colonial, responsável por apagar vivências e práticas espaciais produzidas ao sul global.

Palavras-Chave: determinismo; discurso-geopolítico; geopolítica-decolonial.

\begin{abstract}
The expansion of the modern/colonial system from the fifteenth century originated the construction of a differentiation between colonizers and colonized based on the idea of race. This became the founding element of the relationships of domination, articulating and crystallizing the geographical power: Europe and the Americas, White and Black; Indian; Half-breed; Yellow, Occident and Orient; Developed and Underdeveloped. The aim of this article then is to analyze geopolitical thesis of the nineteenth century founded initially around the prism of the
\end{abstract}

${ }^{1}$ O presente artigo foi realizado com apoio da Coordenação de Aperfeiçoamento de Pessoal de Nível Superior Brasil (CAPES) - Código de Financiamento 001. 
environmental determinism, in order to understand if and how its discourse legitimate at that time the new wave of colonialism, the European rule over the world and the intensification of colonial violence. Therefore, it will be carried out a short genealogy of the environmental determinist discourse in the western thought, an analysis of its influence in the thesis of Friedrich Ratzel, Ellen Semple e Ellsworth Huntington and some of its parallels and counterpoints with French geopolitics, specially with the thinking of Paul Vidal de la Blache. This article is expected to amplify the call for the construction of a subaltern geopolitics that points out the vices of the modern/colonial geopolitical discourse, responsible to erase the spatial practices produced on the global south.

Key words: determinism; geopolitical-discourse; decolonial-geopolitics.

\section{INTRODUÇÃO}

O discurso geopolítico moderno/colonial se constrói a partir do encontro ibérico com o que viria a ser as Américas no início do século quinze e é fundante da colonialidade do poder e do saber e do padrão de poder mundial que se cristaliza em um sistema-mundo em formação. Naquele momento, passou-se a representar espacialmente o mundo de forma a diferenciar a Europa qualitativamente do resto do planeta tanto pela cultura e civilidade de seu povo quanto pelo contexto geográfico - caracterizado, por exemplo, pelo predomínio de clima temperado - em que estava imerso. Retomando a filosofia clássica, em especial Hipócrates e Aristóteles, pensadores como o padre Alberto Magno (no medievo), Jean Bodin (na renascença), Kant e Montesquieu (no iluminismo) contribuíram de fato para justificar, cada qual em sua época, a superioridade da civilização europeia e o domínio e a violência colonial em âmbito global.

Em fins do século dezenove, em meio à revolução científica e ao novo processo de expansão colonial, o discurso geopolítico moderno/colonial já presente no pensamento ocidental se torna conhecimento científico e é fundamental para a consolidação da Geografia, como nos destaca Clerc (2014, p. 135) ao estudar especificamente a ligação entre o colonialismo e a afirmação da disciplina na França. Dessa maneira, se indaga neste artigo sobre o modo pelo qual o discurso geopolítico moderno/colonial cientificado sobre o prisma do determinismo racial e geográfico dá validade e justifica a articulação espacial do poder cristalizada no sistema-mundo. Argumenta-se que isso se dá a partir da naturalização da expansão imperialista e da violência colonial, transformados não em fenômenos singulares ou excepcionais, mas em fatos geográficos despolitizados que representam indicador de seleção natural e processo evolucionário da sociedade humana.

Sob influência das raízes deterministas do pensamento ocidental e a partir da Biologia, em especial as teorias da evolução de Lamarck e Darwin, supostamente comprovou-se cientificamente que, para além de diferenças somáticas, as diferenças raciais incidiam também sobre a índole do sujeito, determinando naturalmente o caráter inferior ou superior de agrupamentos humanos. Da mesma sorte que fatores geográficos como o clima e o solo oferecem condições para o progresso e a modernização da sociedade humana, sendo o clima temperado superior ao tropical nesta empreitada e definidor do destino de seus ocupantes. Isso fortaleceu e justificou a dependência estrutural do sul global e a violência colonial tanto em termos sociopolíticos e econômicos, quanto em termos epistêmicos. 
O objetivo deste artigo, então, é o de analisar o caráter eurocêntrico das teses geopolíticas fundadas sobre o prisma do determinismo racial e geográfico de forma a compreender se seu discurso de autoridade legitima a expansão do sistema moderno/colonial e a articulação espacial do poder cristalizada em conseguinte, tendo em vista que remete a classificação social de agrupamentos humanos a partir da ideia de raça e de seu ambiente geográfico.

Em vista disto, o texto será estruturado em duas partes principais, para além desta introdução e das considerações finais. Em primeiro lugar, tendo como ponto de partida o pensamento decolonial latino-americano, será apresentado de forma breve o que se entende por sistema moderno/colonial e colonialidade do poder e apreendido o contexto sócio histórico do surgimento da geopolítica, de modo a destacar a maneira pela qual o saber geopolítico foi sendo desenhado e seu discurso tornou-se dispositivo estratégico para o exercício de poder social. Por fim, será demonstrada, de maneira sintética e a partir de revisão bibliográfica, a genealogia do determinismo racial e geográfico no pensamento ocidental e analisada e desconstruída sua influência nas teses geopolíticas de Ratzel, Ellen Semple, Ellsworth Huntington e Paul Vidal de la Blache.

\section{A COLONIALIDADE DO PODER, A EXPANSÃO DO SISTEMA MODERNO/COLONIAL E A GÊNESE DA GEOPOLÍTICA}

O pensamento decolonial latino-americano se apresenta como ponto de partida para a compreensão do discurso geopolítico e da articulação espacial de poder construída, legitimada e cristalizada tanto por suas teses clássicas, quanto por suas análises contemporâneas. Destaca-se que o conceito de colonialidade transcende a ideia de colonialismo e ressignifica o que é viver em um mundo pós-colonial. As ondas de independência compreenderam, de fato, o fim do direto domínio políticojurídico exercido pelos Estados centrais. No entanto, não romperam com a estrutura global de dominação e as hierarquias raciais, étnicas e epistêmicas fundadas pela colonialidade (CASTRO-GÓMEZ; GROSFOGUEL, 2007, p. 13).

O encontro ibérico com o que viriam a ser terras americanas no século quinze é o contexto de gênese da colonialidade e do novo padrão de poder em escala global que, por suposto, não se finda com as ondas de descolonização nos séculos dezenove e vinte. A partir de Quijano (2000, p. 201-203), sua institucionalização se dá em dois eixos fundamentais. Em primeiro lugar, pela construção da ideia de raça associada às hierarquias históricas, culturais e sociais bem definidas. Mesmo se a relação entre negros, brancos e mestiços seja anterior à expansão colonial, ela adquiriu, naquele momento, materialidade e passou a naturalizar a violência da dominação e conquista das Américas. Não vítimas de um conflito entre iguais, os sobreviventes foram despojados de sua própria cultura e civilizados em termos europeus. Não mais Tupi ou Aruaque, mas todos índios. Não mais, lorubá ou Fulanis, mas todos negros. A ideia de raça passa, então, a dar sentido às relações de poder estabelecidas inicialmente na América Latina e mais 
tarde a nível global (QUIJANO, 2006, p. 348) e que são justificadas por autores clássicos como, dentre outros, Jean Bodin, Montesquieu e Kant ${ }^{2}$.

Em segundo lugar, pela construção de nova divisão racial do trabalho no mercado mundial na qual "as raças 'superiores' ocupam as posições melhor remuneradas, enquanto as 'inferiores' exercem os trabalhos mais coercitivos e pior remunerados" (CASTRO-GÓMEZ; GROSFOGUEL, 2007, p. 16). Aos índios fora imposta a servidão. Os negros foram tomados por escravos e os brancos civilizados permaneceram livres para agir como agentes econômicos de uma economia capitalista em expansão (OUIJANO, 2000, p. 204-205). Tem-se ali a origem da dependência estrutural do sul ao norte global, já que o novo padrão de poder fundamentado na hierarquia de raça e na divisão racial do trabalho possibilitou o acúmulo de recursos nas mãos do branco europeu capitalista, processo reforçado e reproduzido a nível global pela posterior expansão do sistema-mundo moderno/colonial (MIGNOLO, 2002; QUIJANO, 2000; 2006).

De acordo com Quijano (2000, p. 208), o conceito de sistema-mundo proposto por Immanuel Wallerstein só pode ser entendido a partir da construção do duplo movimento fundante da colonialidade do poder: a hierarquia de raças e a divisão racial do trabalho. Isto é, a estruturação das relações centroperiferia em nível mundial está relacionada com a sistematização da colonialidade do poder e o estabelecimento de uma diferença colonial primeira (CASTRO-GÓMEZ; GROSFOGUEL, 2007, p. 19). Da mesma maneira em que a colonialidade do poder, o sistema-mundo moderno se funda na construção social do continente americano e na institucionalização do circuito colonial atlântico, tendo seu padrão estrutural sido reproduzido quando da expansão do sistema colonial a nível global (OUIJANO; WALLERSTEIN, 1992, p. 549-550). Nesse sentido, aponta Mignolo (2002, p. 81), é ali onde se encontram e se entrelaçam em um mesmo processo a modernidade, a colonialidade e o capitalismo.

É a partir da construção da diferença colonial e da colonialidade do poder, então, que se estrutura o moderno Sistema de Estados e o poder é articulado espacialmente em nível sistêmico. Durante o período colonial o sul global colonizado representava a periferia do sistema e, na medida em que as ondas de descolonização não colocaram fim a colonialidade do poder, a hierarquia permanece no período pós-independência (QUIJANO; WALLERSTEIN, 1992). Por esse ângulo, destacam Quijano e Wallerstein (1992, p. 550), os processos de independência, ao conformarem os novos Estados na antiga hierarquia do sistema-mundo, não contribuíram para findar a colonialidade, transformando somente sua forma de manifestação. O ordenamento e a articulação de poder norte-sul permaneceram cristalizados, sem maiores distúrbios no que concerne a dependência estrutural e a violência tanto em termos sociopolíticos e econômicos, quanto em termos epistêmicos (QUIJANO, 2000; MIGNOLO, 2002).

\subsection{A EXPANSÃO DO SISTEMA MODERNO/COLONIAL E A GÊNESE DA GEOPOLÍTICA}

Yves Lacoste ainda na década de 1960 indica que, embora presumida a inocência do conhecimento geográfico pela "Geografia dos professores", ele é, sobretudo, um saber estratégico

\footnotetext{
${ }^{2}$ Em relação especificamente a Kant, ver Lepe-Carrión (2014).
} 
diretamente relacionado à "política dos Estados maiores" (LACOSTE, 1993, p. 26). O discurso da geografia não é inócuo e não se coloca, por exemplo, de fora do nexo saber-poder. O argumento é que ele não somente lida com as políticas de poder, mas, como todo saber, é em si mesmo uma forma de poder (TUATHAIL, 1996, p. 1). Ao fim e ao cabo, a Geografia, e em especial a geopolítica, imagina, constrói e organiza o espaço mundial de acordo com os interesses do emitente e dentro de um contexto fundado pela colonialidade do poder (QUIJANO, 2000).

Apoiado em Agnew e Corbridge (1995, p.47), entende-se por discurso geopolítico a maneira pela qual o espaço geográfico é construído, comunicado e incorporado na prática dos Estados em diferentes períodos históricos. Ele se compõe de um duplo processo no qual as representações espaciais são produzidas e posteriormente adotadas pela elite política de modo a organizar o mundo em múltiplas áreas, compostas por distintos grupos sociais e imersas em diferentes situações geográficas. Nesse sentido, é a partir do discurso geográfico que

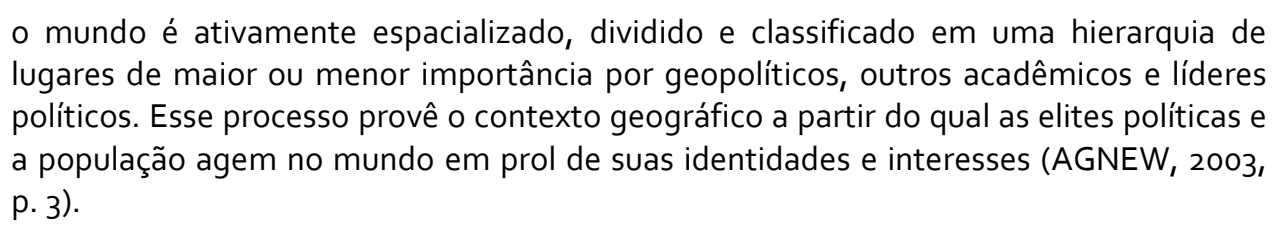

Apesar da Geografia como disciplina científica ter origem, de fato, somente no século XIX e do termo geopolítica ter sido cunhado por Rudolf Kjellén apenas em 1889, o discurso geopolítico moderno tem sua origem no período das grandes navegações, no encontro ibérico com o que viria a ser as Américas (AGNEW; CORBRIDGE, 1995, p. 49). Tomando como pressuposto a hierarquia de raças, dividiuse o mundo em dois grandes espaços geográficos interconectados pelo escopo do sistema moderno/colonial: de um lado o espaço moderno/civilizado europeu; de outro o espaço primitivo/bárbaro das colônias (TUATHAIL, 1996, p. 41). Dessa maneira, ali se começou a construir representação espacial do mundo em que se diferenciava a Europa qualitativamente do resto do planeta tanto pela cultura e civilidade de seu povo quanto pelo contexto geográfico - caracterizado, por exemplo, pelo predomínio de clima temperado - em que estava imerso.

Quando da revolução no campo das ideias e da construção do conhecimento ao fim do século XIX, tornou-se mister dotar o discurso geopolítico moderno de autoridade científica e, nesse sentido, a disciplina se institucionaliza no norte global, em especial na Alemanha, França, Inglaterra e Estados Unidos (TUATHAIL, 1996, p. 16). Em contexto de intensificação das rivalidades coloniais, formalizou-se cientificamente a representação espacial do sistema de Estados de modo a desenvolver e justificar cursos de ação adotados pelo centro em âmbito internacional (AGNEW, 2003, p. 3). Este conhecimento geopolítico, construído e atrelado diretamente às realidades e aos interesses de seus emitentes, naturalizou a colonialidade do poder e a violenta expansão do sistema mundo moderno/colonial (QUIJANO, 2000).

Especialmente a partir de 1870, os Estados europeus alargaram seu domínio colonial por todo o globo em moldes imperialistas. Somente no continente africano foram estabelecidas por volta de trinta 
novas colônias e protetorados (TUATHAIL, 1996, p. 16) e, em 1914, as grandes potências europeias, em conjunto com Japão e EUA, passaram a controlar cerca de 85\% da superfície do planeta (AGNEW, 2003, p. 52). Nos termos de Mackinder (1904) ali se tem origem, na política internacional, a época póscolombiana, na medida em que todos os espaços em branco do mapa foram já conquistados e ocupados pela civilização ocidental, tornando o sistema moderno/colonial verdadeiramente global. De qualquer maneira, o próprio argumento de Mackinder já é revelador da colonialidade por trás do discurso geopolítico cientificado, pois este pressupõe a existência anterior de espaços a descobrir desocupados de qualquer valor ou cultura e agora absorvidos e incorporados ao mapa-múndi pela civilização ocidental (TUATHAIL, 1996, p. 20).

De modo a tornar científico o discurso geopolítico concebido durante a primeira expansão colonial, subjaz ao argumento da geopolítica clássica a influência tanto de autores clássicos como Hipócrates, Aristóteles, Jean Bodin e Kant, quanto dos trabalhos de Lamarck e Darwin, proposição a ser discutida de forma mais direta na próxima seção. Em suposição comprovou-se cientificamente que, para além de diferenças somáticas, as diferenças raciais incidiam também sobre a índole do sujeito, determinando naturalmente caráter inferior ou superior a agrupamentos humanos. Da mesma sorte, fatores geográficos como o clima e o solo oferecem condições para o progresso e a modernização da sociedade humana, sendo o clima temperado superior ao tropical nesta empreitada e definidor do destino de seus ocupantes (AGNEW, 2003, p. 26). Deste ponto de vista, a expansão imperialista e a violência colonial não são fenômenos singulares ou excepcionais, mas fatos geográficos despolitizados que representam o curso natural da vida (AGNEW; CORBRIDGE, 1995, p. 57).

É nesse sentido que Lacoste denuncia a "geografia dos Estados-maiores" como estratégia de poder e instrumento de dominação (LACOSTE, 1993, p. 26). Mesmo que o autor não ingresse em searas decoloniais, seu argumento permite, preliminarmente, explorar a maneira pela qual a partir do discurso científico da geopolítica, a elite política age e justifica as hierarquias entrepostas pela colonialidade do poder, cristalizando articulação espacial herdada do período colonial. Lacoste, indica Costa (1992, p. 259), contribui ativamente para o surgimento de uma geopolítica crítica "comprometida eticamente com a paz, a democracia e a justiça social", que vai se consolidar por volta dos anos 1990 a partir do trabalho de Gearoid Ó Tuathail, John Agnew e, dentre outros, Simon Dalby e da publicação em 1996 do dossiê Critical Geopolitics (Geopolítica Crítica) na revista Political Geography (DALBY; TUATHAIL, 1996).

A Geopolítica Crítica, entretanto, mesmo que seu enfoque emancipatório contraste com aquele da geopolítica tradicional, continua a ser uma maneira ocidental de olhar o mundo e representar o espaço, não sendo suficiente para decolonizar a disciplina e dar voz aos discursos e às práticas geopolíticas produzidas na periferia (SHARP, 2011, p. 21). Desse ponto de vista, Sharp (2011, p. 21) aponta para a necessidade de se construir uma geopolítica subalterna a partir das vivências dos silenciados e marginalizados pelo discurso geopolítico moderno/colonial, como a geopolítica panafricana de Julius Nyerere em uma Tanzânia pós-colonial (SHARP, 2013). Da mesma maneira, Jennifer Hyndman (2001) discute a necessidade de se construir uma geopolítica feminista que emancipe a violência de gênero presente no discurso geopolítico tradicional e em suas práticas políticas 
espacializadas e Sara Koopman (2011) trabalha o conceito de alter-geopolítica para compreender de que maneira alternativas não-violentas estão sendo pensadas e postas em prática em nível local para garantir a segurança da população civil vivendo em Estados marcados por violentos conflitos sociais, como na Colômbia, na República Democrática do Congo e em Uganda.

\section{O DETERMINISMO RACIAL E GEOGRÁFICO NO PENSAMENTO OCIDENTAL E O DISCURSO GEOPOLÍTICO MODERNO/COLONIAL CIENTIFICADO}

Às origens clássicas do pensamento ocidental são de maneira geral fundamentadas na Grécia Antiga. É dali, portanto, que se inicia breve genealogia do determinismo racial e geográfico. No pensamento grego, tem-se principalmente em Aristóteles e Hipócrates fontes fundamentais para a apreensão das raízes do determinismo (GOSSETT, 1997, p. 3-16; LIVINGSTONE, 2011, p. 370). Ambos os filósofos buscaram, a partir do clima, comparar os costumes (nómoi), a compleição (morphé) e a forma física (êidos) dos povos europeus, do povo helênico e dos povos asiáticos (CAIRUS, 2005, p. 93; GOSSET, 1997, p. 3-16). De modo a justificar as bases filosóficas de sua comparação, Hipócrates afirma que:

o que ocorre com a terra é semelhante ao que ocorre, de outra parte, com os homens. Pois, onde as estações produzem mudanças maiores e mais frequentes, ali também a região é mais selvagem e mais irregular, e encontrarás montanhas maiores, com bosques, platôs e alagados. Mas onde as estações não mudam muito, nesses lugares, a região é mais regular. Assim é também em relação aos homens, se se observar bem. Pois há as naturezas que se parecem com as montanhas arborizadas e cheias de água, as que se parecem com os solos pobres e sem água, as que se parecem com os solos mais pantanosos e brejos, e também as que se parecem com uma planície sem vegetação e seca. As estações que mudam a natureza da compleição são diferentes. Se elas diferem grandemente entre si, as diferenças tornam-se também grandes nos aspectos físicos (CAIRUS, 2005, p. 104).

Aristóteles, por sua vez, após realizar sua análise, chega à conclusão de que, por um lado, os povos Europeus, vivendo em ambiente frio e seco, são espirituosos e livres, mas pouco inteligentes e incapazes de se organizarem politicamente; por outro lado, os povos asiáticos, vivendo em clima quente e úmido, são bastante inteligentes, mas pouco espirituosos e vivem em estado natural de subjugação; e, enfim, que os helênicos, por viver em clima temperado, são tanto espirituosos, quanto inteligentes, vivem em liberdade e são capazes de se organizar politicamente (GOSSETT, 1997, p. 6-7).

Durante o medievo, é possível se notar a influência do determinismo helênico a partir da propagação da teoria humoral. Argumentava-se que o humor e outras qualidades dos povos estavam relacionados com os diferentes tipos de clima - quente, frio, seco e úmido (LIVINGSTONE, 2011, p. 370). Como destaca Livingstone (2011, p. 370), é possível se perceber o argumento, por exemplo, na ideia do padre Alberto Magno (d.C 1193-1280) de que os atributos humanos são condicionados por diferentes klimatas. Da mesma maneira, durante a renascença, Jean Bodin retoma as teses deterministas analisando a influência da situação geográfica e da astrologia nas diferenças observáveis entre os povos humanos (GOSSETT, 1997, p. 14). Para o filósofo, por exemplo, os habitantes de terrenos montanhosos 
tendem a ser rebeldes e violentos; os habitantes de planícies tendem a ser compassivos e governados por déspotas; os que vivem na costa tendem a ser aristocráticos e democratas; Marte torna os povos do norte da Europa belicosos e inventivos, Saturno os povos do sul espirituosos e inteligentes e Júpiter os povos temperados mais aptos ao manejo dos negócios e da política (GOSSETT, 1997, p. 14).

Já durante o lluminismo, o determinismo racial e geográfico pode ser observado a partir do pensamento de filósofos como Montesquieu e Kant (LIVINGSTONE, 2011, p. 371). Por um lado, Montesquieu (2000), dispondo de herança helênica, debita à situação geográfica as diferenças em termos culturais, morais, de caráter e do sistema legal. É míster o título do capítulo segundo do livro décimo quarto de $O$ Espírito das leis: "Quanto os homens são diferentes nos diversos climas" (MONTESOUIEU, 2000, p. 239). Em passagem de dito capítulo, destaca o autor que

um homem num lugar quente e fechado, ele sofrerá...uma fraqueza muito grande no coração. Se, nessas circunstâncias formos propor uma ação arriscada, penso que o acharemos muito pouco disposto; sua fraqueza presente provocará certo desencorajamento em sua alma; temerá tudo, porque sentirá que não pode nada. Os povos dos países quentes são tímidos assim como os velhos; os dos países frios são corajosos como os jovens (MONTESQUIEU, 2000, p. 240).

Para Montesquieu, a título de exemplo, essas características podem ser encontradas na Índia, onde os povos são "naturalmente sem coragem; os próprios filhos dos europeus nascidos nas índias perdem a coragem que teriam em seu clima. (...)" (MONTESOUIEU, 2000, p. 242-243). Ali, prossegue, "os homens submetem-se a males inacreditáveis" e "as mulheres queimam a si mesmas" (MONTESQUIEU, 2000, p. 243).

Do mesmo modo, Kant (2010, p. 24), em Das diferentes Raças Humanas, argumenta que, apesar do homem por natureza ser capaz de sobreviver por adaptação a qualquer situação geográfica, o clima temperado do velho mundo é aquele no qual se encontra a maior riqueza e provê o melhor ambiente para o desenvolvimento humano. É claro em Kant, nesse sentido, o estabelecimento de hierarquia entre as raças e posicionamento contrário a miscigenação. Para o filósofo, o clima temperado europeu influenciou o surgimento de linhagem capaz de prosperar a qualquer adversidade (KANT, 2010, p. 24). Em vista disso, aponta Lepe-Carrión (2014, p.69), que Kant estabelece aos europeus o papel de vetores do gênero humano, naturalizando a diferença colonial ao determinar serem seu dever moral levar a civilização e o progresso aos povos selvagens vivendo em clima quente e úmido.

Durante a revolução científica no século dezenove, as ciências sociais, em busca de constantes e leis naturais que permitiriam sua consolidação, são influenciadas pelas teorias da evolução de Darwin e Lamarck. A analogia organicista e as hipóteses causais baseadas na Biologia contribuíram para a transcrição das teses deterministas clássicas em termos científicos. Ao estabelecer o papel dos homens no ambiente natural, o chamado darwinismo social de fato contribuiu para a afirmação e o desenvolvimento da Sociologia, da Antropologia, da História e, sem dúvida, da Geografia e da geopolítica. Nesse sentido, tornou-se a pedra sobre a qual o pensamento geográfico pode ser edificado e a base para o desenvolvimento de teses geopolíticas orientadas sobre o prisma do determinismo racial e geográfico (LIVINGSTONE, 2011, p. 374; PEET, 1985, p. 315). 
Fundamentando o discurso em hipóteses organicistas, a competição entre os Estados e a expansão daqueles mais bem adaptados naturalizou-se como parte de um processo evolucionário. Isto é, o discurso geopolítico moderno/colonial passou a ter bases científicas e a dominação ocidental foi legitimada ao ser compreendida como momento necessário no processo de evolução da sociedade humana (PEET, 1985, p. 327). Princípios que podem ser identificados antes de tudo na geopolítica alemã de Friedrich Ratzel (BASSIN, 1987, p. 474), na transcrição do argumento para a geopolítica estadunidense por Ellen Semple (1911) e Ellsworth Huntington (1924) e, em certo sentido, na geopolítica francesa a partir dos trabalhos de Albert Demangeon, Marcel Dubois e, dentre outros, Paul Vidal de la Blache.

A partir de Durkheim (1899, p. 3-4), argumenta-se que Ratzel se preocupa com três principais classes de problema na construção de seu discurso geográfico. Primeiro, estabelecer de que maneira os homens se distribuem sobre a superfície da terra e como eles passaram a fazer parte de diferentes grupos sociais. Em segundo lugar, explicar essa distribuição e o contínuo movimento dos homens e da sociedade sobre o espaço geográfico. Enfim, compreender a influência e a relação simbiótica entre a sociedade humana e seu território. De modo a responder a tais indagações, Ratzel vai construir seu argumento a imagem dos conceitos de evolução orgânica e seleção natural tomados dos escritos de Darwin popularizados na Europa quando da publicação de A Origem das Espécies (1859) (PEET, 1985, p. 316).

Partiu-se do princípio de que "a sociedade humana só poderia ser compreendida a partir das mesmas leis que governam o mundo natural" e, portanto, havia de se criar um esquema geográfico no qual o próprio Estado era apresentado como um organismo vivo (BASSIN, 1987, p. 477). À vista disso, o Estado foi descrito como sendo formado por um conjunto homogêneo de pessoas vivendo em um espaço geográfico a partir do qual é retirada a energia necessária para sua sobrevivência (PEET, 1985, p. 316). É somente a partir desse Lebensraum (ou espaço vital) que o Estado pode se consolidar e sua evolução ou desenvolvimento está profundamente relacionado com o processo de expansão (aggrandizement) territorial (BASSIN, 1987, p. 477).

Como aponta Durkheim (1899, p. 7), o Estado, para Ratzel, teria sede de espaço e, de forma a amadurecer, deve impreterivelmente progredir em termos territoriais. À medida em que a sociedade cresce, há uma demanda cada vez maior por recursos e, portanto, pelo alargamento do espaço vital. Caso o Estado não consiga expandir territorialmente ou perca parte de seu Lebensraum, eventualmente entrará em declínio (BASSIN, 1987, p. 479; PEET, 1985, p. 316-317). Isso significa dizer que o alargamento dos Estados maiores deve ocorrer a partir de um processo contínuo e natural de amalgamação do espaço vital de Estados menores. Dessa maneira, mesmo que, em um primeiro momento, Ratzel não se utilize do termo raça para justificar a expansão e o imperialismo ocidental, seu discurso geopolítico de fato justifica a dominação colonial como o curso natural de um processo orgânico de evolução e seleção natural das civilizações mais avançadas (BASSIN, 1987, p. 479).

No que se refere à geopolítica estadunidense, no discurso geopolítico realçado nos trabalhos de Ellen Semple e Ellsworth Huntington é clara a influência tanto do determinismo racial e geográfico, 
quanto da tese de Ratzel. Semple, por exemplo, explicitamente declara em Influences of Geographic Environment (1911) se basear na Antropogeografia de Ratzel e, a partir de Peet (1985, p. 317), pode ser considerada a grande responsável por introduzir suas ideias no mainstream do pensamento geográfico dos Estados Unidos. Assim como o geógrafo alemão, Semple (1911) acredita que não há como compreender as sociedades humanas aparte das leis que regem o mundo natural. Premissa que pode ser observada, por exemplo, quando argumenta que "o homem não pode ser estudado cientificamente fora do solo em que cultiva, das estradas em que viaja e dos mares em que comercia, da mesma maneira em que o urso polar e o cactos do deserto não podem ser compreendidos separados de seu hábitat" (SEMPLE, 1911, p. 2).

Para Semple (1911, p. 2), então, o ambiente geográfico é a mais persistente influência no destino da sociedade humana, no geral, e de suas diferentes raças, em particular, sendo a carga motora do processo de evolução e seleção natural. Por conseguinte, a situação geográfica pode explicar as diferenças em progresso entre a miríade de povos que habitam a Terra. Destacam-se em seu argumento duas formas pelas quais o ambiente natural molda o destino dos homens: de maneira indireta, alterando as características das diferentes raças (costumes, educação, nível intelectual, etc.), e de maneira direta, ao mesmo tempo restringindo e possibilitando as atividades sociais, políticas e econômicas (PEET, 1985, p. 321). Dessa maneira, aponta Semple (1911, p. 2) que "em todo problema histórico são dois os principais fatores explicativos, hereditariedade e meio ambiente, o homem e suas condições geográficas, as forças internas da raça e as forças externas do hábitat", premissa que se aproxima das reflexões, por exemplo, de Hipócrates, Aristóteles, Jean Bodin, Montesquieu, etc.

Assim, o discurso geopolítico de Semple também justifica a expansão e o imperialismo ocidental a partir de causas naturais, apontando especialmente para os efeitos indiretos do ambiente geográfico, ou seja, sua influência nas características das diferentes raças (PEET, 1985, p. 321). O que pode ser apreendido especialmente de seus apontamentos sobre os efeitos do clima no desenvolvimento das sociedades. Para Semple (1911, p. 609), o clima "influencia o nível e o limite do desenvolvimento cultural de cada raça". Argumenta-se que a presença de clima tropical no sul global, em contraste ao clima temperado ao norte, contribui para seu atraso econômico, político e social, sendo indicador suficiente para confirmar tal assertiva o fato de estarem localizadas nessa área tanto as antigas, quanto as (à época) atuais possessões coloniais europeias (SEMPLE, 1911, p. 634). Dessa maneira, o elemento raça será fundante em Semple (1911, p. 634-635) para explicar as relações de dominação e para cristalizar a distribuição de poder fundada pela colonialidade, já que a autora reconhece, como Kant, as benesses do clima temperado (em oposição ao tropical) para o desenvolvimento de formas mais avançadas de civilização.

Em continuidade ao argumento de Semple, Ellsworth Huntington, em Civilization and Climate (1924), destaca, também, supostos efeitos do clima como fator geográfico explicativo das diferenças raciais e da inferioridade da civilização no sul global. Para o autor, as raças são resultado da adaptação natural do ser humano aos diversos contextos geográficos e, resgatando o argumento de Montesquieu, acredita que elas se diferenciam completamente em termos culturais, morais, de caráter e do sistema 
político e legal adotado para organizar a sociedade (HUNTINGTON, 1924, p. 3). Nesse sentido, afirma que "poucos poderiam questionar que raças que herdam soberba capacidade física e mental e uma boa saúde...podem atingir os níveis mais altos de civilização" e que o caso oposto leva justamente à degeneração (HUNTINGTON, 1924, p. 2-3). Enfim, sendo o clima fator determinante para as diferenças raciais, este, logo, também é o elemento explicativo para os diferentes níveis de desenvolvimento entre o norte e o sul global e a justificativa para a dominação colonial (HUNTINGTON, 1924, p. 3).

Em relação à geopolítica francesa, apesar de Lucien Febvre (1949) apresentá-la como afastada do discurso geopolítico determinista da geopolítica alemã e da herança de Friedrich Ratzel, seu discurso não pode ser compreendido como inócuo ou aparte da "geografia dos Estados Maiores" de Lacoste (1993). O período de afirmação da geografia na França em fins do século dezenove será marcado por seu contexto, a derrota para Alemanha na guerra franco-prussiana e a intensificação da expansão colonial europeia, e construirá a representação do espaço geográfico que reflete os interesses de Paris (tanto na Europa, quanto no sistema moderno/colonial). Dessa maneira, será desenvolvida, principalmente, a partir dos trabalhos de Vidal de la Blache uma geopolítica que tanto fundamenta as bases do expansionismo francês, quanto posiciona a França em oposição à Alemanha no jogo político europeu - 0 que não significa que se possa desconsiderar a influência de Ratzel na consolidação de seu pensamento geográfico (CAMPOS, 2014, p. 37).

Como aponta Campos (2014, p.21), Ratzel e sua Antropogeografia contribuíram ao basilar da geopolítica francesa, em geral, e para o trabalho de la Blache, em particular. Em La Géographie politique, à propos des écrits de M. Frédéric Ratzel (1898), por exemplo, o autor de fato demonstra aceitar (com ressalvas) a concepção do Estado como organismo vivo do geopolítico alemão, argumentando ela "representar uma fórmula admirável da lei de desenvolvimento por trás das relações do homem com o solo", mesmo que não se possa abusar de seus princípios (LA BLACHE, 1898, p. 101). Mas, também, o que significaria aceitar por completo as teses ratzelianas em um contexto em que a França havia sido derrotada na guerra franco-prussiana e perdido as províncias de Alsácia e Lorena? De fato, confirmaria a superioridade do povo alemão em relação ao modelo de civilização francês. Nesse sentido, pode-se afirmar que mesmo la Blache não tendo defendido sem pudor a Antropogeografia de Ratzel (em especial no que tange à política internacional europeia), por certo seus imperativos foram levados em consideração quando da análise do papel da França no sistema moderno/colonial (CAMPOS, 2014, p. 37). À vista disso, afirma Ribeiro (2009b, p. 133)

que ao preferir forjar um Vidal "possibilista" (vocábulo que Vidal jamais utilizou), o diretor da Encyclopédie Française [Lucien Febvre] negligenciava um geógrafo cujo raciocínio não abria mão da estratégia, tal como revelam o lamento pela perda de parte do território das Guianas para o Brasil, o acompanhamento da missão militar de seus compatriotas no Peru e a preocupação com o desenvolvimento da colonização francesa e suas fronteiras na África.

Destarte, a distinção proposta por Febvre (1949) entre o determinismo geográfico alemão e o possibilismo francês esconde a influência da expansão imperialista europeia e do colonialismo no discurso geopolítico da França (RIBEIRO, 2009a, p. 26). Para Clerc (2014, p. 135), por exemplo, a 
articulação entre a geopolítica e o colonialismo é fundamental para fundamentação e institucionalização da geografia francesa. Evidência disso é a criação em fins do século dezenove de cadeiras de Géographie Coloniale $^{3}$ - mais tarde transformadas em Géographie Tropicale, o que indica (talvez) vínculo (mesmo que indireto), com o argumento de Semple (1911) e Huntington (1924) -, como a ocupada por Marcel Dubois na Universidade de Paris desde 1893 (CLERC, 2014, p. 136; GINSBURGER, 2017); e a formação de comitês coloniais com participação ativa dos principais geógrafos franceses à época - destaque para o Comité de L'Afrique Française de 189o, do qual Vidal de la Blache era membro atuante - e que tinham por objetivo tanto produzir conhecimento sobre as colônias, quanto "criar um movimento de opinião pública favorável à colonização" (CLERC, 2014, p. 136).

Enfim, retornando a La Géographie politique, à propos des écrits de M. Frédéric Ratzel de la Blache, a naturalização do imperialismo na geopolítica francesa e a sua concepção acerca do colonialismo fica evidente em sua afirmação de que "a Europa moderna [ocidente], sobretudo, é a artesã infatigável de uma obra que tende a uniformizar, senão o planeta como um todo, ao menos algumas de suas zonas", por exemplo, como fez os Estados Unidos que, entre os anos de 1870 e 1889, "converteu suas pradarias em zonas de culturas"4 (LA BLACHE, 1898, p. 103). Subjaz em La Blache (1898), então, não somente o entendimento presente em autores clássicos, como Aristóteles, Jean Bodin, Montesquieu, Kant, ou modernos, como Ratzel, Semple e Huntington, de que a civilização europeia é o berço da mais avançada das civilizações, mas também tem o dever moral de preencher com cultura (civilizar) o resto do planeta. Em consequência, seu discurso geográfico de fato justifica, também, a relação de dominação estabelecida entre o norte e o sul global e naturaliza a expansão imperialista e a violência colonial.

\section{Considerações Finais}

O objetivo deste artigo foi o de analisar teses geopolíticas fundadas sobre o prisma do determinismo racial e geográfico de forma a compreender de que maneira seu discurso de autoridade legitima, ao final do século dezenove e início do século vinte, a expansão do sistema moderno/colonial e a articulação espacial do poder cristalizada em conseguinte, tendo em vista que remete a classificação social de agrupamentos humanos a partir da ideia de raça e de seu ambiente geográfico. Para tanto, foi levantado o argumento proposto por Friedrich Ratzel, representando a geopolítica alemã, Ellen Semple e Ellsworth Huntignton, representando a geopolítica estadunidense, e Paul Vidal de la Blache, representando a geopolítica francesa.

A partir da análise se chegou à conclusão preliminar de que, recuperando as raízes deterministas do pensamento ocidental desde Aristóteles até Kant e sob influência da Biologia, de fato o discurso geopolítico moderno/colonial cientificado naturalizou a colonialidade do poder e a violência epistêmica.

\footnotetext{
3 Nesse sentido, Clerc (2014, p. 136) aponta a partir de dados da Annales de Géographie que "no curso do ano universitário de 1889-1990, dentre as vinte universidades francesas nas quais a Geografia era ensinada, mais da metade contavam com cadeira de geografia colonial".
}

${ }^{4}$ Ego Extermino, ver Grosfoguel (2016). 
Mesmo que, por exemplo, la Blache não invoque diretamente o elemento raça, a diferença de Semple e Huntington, para explicar a dominação europeia, seu discurso geopolítico também é composto em parte (não sem ressalvas relativas principalmente à política continental europeia) por argumento organicista que sublinha a superioridade da civilização ocidental e sua posição no sistema moderno/colonial.

Mesmo após toda ponderação e reparo sobre o discurso geopolítico moderno trazido especialmente a partir de Yves Lacoste e dos estudos em geopolítica crítica, o determinismo continua ainda hoje a ser a base de algumas obras que, por certo, repercutiram na academia desde os anos 1990. Por exemplo, o trabalho de Samuel Huntington (1996) em seu hoje seminal O Choque das Civilizações ou Jared Diamond (1997) com Armas, Germes e Aço. Mais recentemente, dentro das Relações Internacionais, Dominic Johnson e Monica Toft (2014), em artigo publicado na International Security, buscaram uma vez mais na Biologia a explicação para os padrões de violência e de uso da força em conflitos territoriais. Destaca-se, ainda, que padrões de violência epistêmica e a colonialidade do poder ainda estão ocultos no discurso geopolítico produzido no norte global e mesmo dentro da própria geopolítica crítica. Espera-se, portanto, ter ampliado o chamado de Sharp (2011) para necessidade de se construir uma geopolítica subalterna que aponte para as vicissitudes do discurso geopolítico moderno/colonial, responsável por apagar discursos e práticas geopolíticas produzidas ao sul global.

Artigo recebido em 01 ago 2018.

Aprovado em 11 nov 2018.

\section{REFERÊNCIAS}

AGNEW, John. Geopolitics: revisioning world politics. 2 ed. Londres: Routledge, 2003.

AGNEW, John; CORBRIDGE, Stuart. Mastering Space: Hegemony, territory and international political economy. Londres/Nova York: Routledge, 1995.

BASSIN, Mark. Imperialism and the nation state in Friedrich Ratzel's political geography. Progress in Human Geography, v.11, n.4, p.473-495, 1987.

CAIRUS, Henrique. Ares, águas e lugares. In: CAIRUS, Henrique; RIBEIRO JR, Wilson. Textos hipocráticos: o doente, o médico e a doença. Rio de Janeiro: Editora FIOCRUZ, 2005.

CAMPOS, Rui Ribeiro de. Análise crítica da obra de Vidal de la Blache e de sua influência no ensino de geografia no Brasil. 2014. 436f. Relatório (Pós-Doutorado) - Universidade Estadual de Campinas, Faculdade de Educação, Campinas.

CASTRO-GÓMEZ, Santiago; GROSFOGUEL, Ramón. Prólogo: giro decolonial, teoría crítica y pensamiento heterárquico. In: CASTRO-GÓMEZ, Santiago; GROSFOGUEL, Ramón. El giro decolonial: Reflexiones para una diversidad epistémica más allá del capitalismo global. Bogotá: Siglo del Hombre Editores, 2007 
CLERC, Pascal. Des connaissances pour l'action : la géographie coloniale de Marcel Dubois et Maurice Zimmermann. Revue germanique internationale, v.20, p.135-146, 2014.

COSTA, Wanderley M. da. Geografia Política e Geopolítica. São Paulo: Editora Hucitec, 1992.

DALBY, Simon; TUATHAIL, Gearóid. Editorial Introduction. The critical geopolitics constellation: problematizing fusions of geographical knowledge and power. Political Geography, v.15, n.6/7, p.451-456, 1996.

DIAMOND, Jared. Guns, Germs and Steel: The fates of human societies. New York: W. W. Norton \& Company, 1999.

DURKHEIM, Émile. Friedrich Ratzel, Antropogéographie: Compte-rendu. 1889. Disponível em: < http://classiques.uqac.ca/classiques/Durkheim_emile/ratzel_anthropo_geographie/ratzel_anthropo_geo. html>. Acesso em 08 abr. 2018.

FEBVRE, Lucien. La terre et l'évolution humaine: Introduction géographique à l'histoire. Paris: Éditions Albin Michel, 1949

GINSBURGER, Nicolas. Des îles grecques à la géographie coloniale : Marcel Dubois à la conquête de la Sorbonne (1876-1895). Cybergeo: revue européene de géographie [online], a.22, s/p, 2017. Disponível em : $<$ https://journals.openedition.org/cybergeo/28368>. Acesso em 8 abr. 2018

GOSSETT, Thomas. Race: The history of an idea in America. New York: Oxford University Press, 1997.

GROSFOGUEL, Ramón. A estrutura do conhecimento nas universidades ocidentalizadas: racismo/sexismo epistêmico e os quatro genocídios/epistemicídios do longo século XVI. Sociedade e Estado, v.31, n.1, p.25-49, 2016.

HUNTINGTON, Ellsworth. Civilization and Climate. $3^{\mathrm{a}}$ ed. New Haven: Yale University Press, 1924.

HUNTINGTON, Samuel. The Clash of Civilizations and the Remaking of World Order. New York: Simon \& Schuster, 1996.

HYNDMAN, Jennifer. Towards a feminist geopolitics: The Inaugural Suzanne Mackenzie Memorial Lecture. The Canadian Geographer, v.45, n.2, p.210-222, 2001.

JOHNSON, Dominic; TOFT, Monica. Grounds of war: the evolution of territorial conflict. International Security, v.38, n.3, p.7-38, 2014 .

KANT, Immanuel. Das diferentes raças humanas. Trad. Alexandre Kahn. Kant e-Prints, v.5, n.5, p.10-26, 2010.

KOOPMAN, Sara. Alter-geopolitics: other securities are happening. Geoforum, v.42, n.3, p.274-284, 2011. 
LA BLACHE, Paul Vidal de. La Géographie politique, à propos des écrits de M. Frédéric Ratzel. Annales de Géographie, v.7, n.32, p.97-111, 1898.

LACOSTE, Yves. Geografia: isso serve, em primeiro lugar, para fazer a guerra. $3^{\text {a }}$ ed. Trad. Maria Cecília França. Campinas: Papirus, 1993.

LEPE-CARRIÓN, Patricio. Racismo filosófico: el concepto de 'raza' en Immanuel Kant. Filosofia Unisinos, v.15, n.1, p.67-83, 2014 .

LIVINGSTONE, David. Environmental Determinism. In: AGNEW, John; LIVINGSTONE, David (eds.). The SAGE Handbook of Geographical Knowledge. Londres: SAGE, 2011.

MACKINDER, Halford. The Geographical Pivot of History. The Geographical Journal, v.23, n.4, p.421-437, 1904 .

MIGNOLO, Walter. The Geopolitics of Knowledge and the Colonial Difference. The South Atlantic Quarterly, v.101, n.1, p.57-96, 2002.

MIGNOLO, Walter. El pensamiento decolonial: desprendimento y apertura. In: CASTRO-GÓMEZ, Santiago; GROSFOGUEL, Ramón. El giro decolonial: Reflexiones para una diversidad epistémica más allá del capitalismo global. Bogotá: Siglo del Hombre Editores, 2007.

MONTESQUIEU, Charles de S. O Espírito das Leis. Trad. Cristina Murachco. São Paulo: Martins Fontes, 2000 .

PEET, Richard. The social origins of Environmental Determinism. Annals of the Association of American Geographers, v.75, n.3, p.309-333, 1985.

QUIJANO, Aníbal. Colonialidad del poder, eurocentrismo y América Latina. In: LANDER, Edgardo (org.). La colonialidade del saber: eurocentrismo y ciencias sociales. Buenos Aires: CLACSO, 2000.

QUIJANO, Aníbal. Don Quijote y los molinos de viento em América Latina. Investigaciones Sociales, v.10, n.16, p.347-368, 2006.

QUIJANO, Aníbal; WALLERSTEIN, Immanuel. Americanity as a concept, or the Americas in the modern world-system. International Social Sciences Journal, v.44, n.4, p.549-557, 1992.

RIBEIRO, Guilherme. Luta pela autonomia e pelo território: geografia e os estados alemão e francês na virada do século xix ao século xx. Mercator, v.8, n.15, p.19-28, $2009 a$.

RIBEIRO, Guilherme. Para ler Geografia ou Geografia segundo Lucien Febvre. Terra Livre, a.25, v.1, n.32, p.121-136, 200gb.

SEMPLE, Ellen C. Influences of Geographical Environment: on the basis of Ratzel's system of antropogeography, Nova York: Henry Holt and Company, 1911. 
SHARP, Joanne. Subaltern Geopolitics: Introduction. Geoforum, v.42, n.3, p.271-273, 2011.

SHARP, Joanne. Geopolitics at the Margins? Reconsidering genealogies of critical geopolitics. Political Geography, v.37, p.20-29, 2013.

TUATHAIL, Gearóid. Critical Geopolitics: the politics of writing global space. Londres: Routledge, 1996. 